\section{To the Editors:}

I read with interest the interview with Dr Rosaralis Santiesteban in the January 2011 issue of MEDICC Review (In the Eye of the Cuban Epidemic Neuropathy Storm: Rosaralis Santiesteban MD, PhD).

First, it represents a well-deserved acknowledgment of Professor Santiesteban's leadership in understanding the optic form of the epidemic disease. I share her well-supported position that Strachan's disease should more properly be called Strachan-Madan disease because of Dr Domingo Madan's major role in describing the condition and elucidating its causes.[1]

During the epidemic I attended patients with optic neuropathy in Santiago de Cuba province; only two of them were diagnosed with Leber's Optic Neuropathy, presenting ten-degree central scotomas.

$\mathrm{Dr}$ Santiesteban provides an interesting chronology of the epidemic in the interview. I would like to underscore that its evolution has been divided into five distinct periods. The first period, corresponding to all of 1992, was characterized by low incidence, with 472 cases reported nationally by year's end. In the second period, from January 1 through March 27, 1993, incidence showed a moderately increasing trend. In the third, from March 28 through April 10, 1993, there was marked increase in new cases. In the fourth, from April 11 through May 28, 1993, the pattern was irregular, beginning the decline in appearance of optic forms while maintaining a marked increase in peripheral forms. From May 29, 1993, through June 30, 1994, incidence of optic forms continued to decline, and incidence of peripheral forms also began to fall.

Recently, I have proposed a sixth period,[2] from July 1, 1994 through the present, a phase of endemicity and rehabilitation of disease sequelae. Finally, I would like to stress that this is the largest nervous system epidemic affecting the Cuban population in last century.

Damaris Fuentes MD MS (dfp@medired.scu.sld.cu)

Neuro-ophthalmologist

1. Santiesteban Freixas R, Pamias González E, Luis González RS, Serrano Verdura C, González Quevedo A, Alfaro Capdegelle I, et al. Neuropatía epidémica. Proposición y argumentación para renombrar la enfermedad de Strachan como Strachan Madan. Rev Neurol. 1997;25(148):1946-9. Spanish.

2. Fuentes Pelier D. Consideraciones actuales sobre la neuropatía epidémica cubana en su forma óptica. MEDISAN. 2011;15(4):536-48. Spanish.

\section{To the Editors:}

Regarding your editorial in the July 2011 issue of MEDICC Review (Equity Matters): the challenges to universalize health care coverage and reduce health inequalities and health care inequities exist everywhere, whether in higher-,[1] middle- or lower-income countries. In some lower- and middle-income countries, these challenges are exponentially larger because of fragmented vital registration systems, limited data collection platforms or lack of comparable survey data. With growing interest in inequalities and inequities worldwide, efforts to monitor inequity trends will require data from multiple sources to analyze geospatial disparities as well as those related to health care, gender, income and minority status.

For low- and middle-income countries, primary data collection through regular integrated household health surveys is possibly the most important source of data for health inequality and equity analyses. WHO supports such work through a number of coordinated efforts, such as the Country Health Systems Surveillance and multi-country studies programs, along with strategic partnerships (US National Institute on Aging, International Household Survey Network and Health Metrics Network).

The WHO Study on Global AGEing and Adult Health has established baseline health levels, determinants and outcomes as well as health care utilization across six countries.[2] In one large multi-country WHO study including 50 lower- and middle-income countries, including Brazil, Ethiopia, Nigeria and Vietnam, differences in health care access contributed substantially to health inequality between the sexes, and generally to health care inequities across countries.[3] A significant contributing factor would be the human element in health care systems, from training to retention of health care professionals.

Paul Kowal (kowalp@who.int)

Ahmad R. Hosseinpoor

Somnath Chatterji

WHO Multi-Country Studies Unit, Geneva

1. Weissman JS, Hasnain-Wynia R. Advancing health care equity through improved data collection. N Engl J Med. 2011;364(24):2276-7.

2. WHO. Multi-country Study on Global AGEing and Adult Health (SAGE) [Internet]. Geneva: World Health Organization (www.who.int/healthinfo/systems/ sage).

3. WHO. World Health Survey [Internet]. Geneva: World Health Organization (www.who.int/healthinfo/systems/survey). 